\title{
Photovoltaic Energy Harvesting under Low Lighting Conditions
}

\author{
Martin Kasemann $^{1}$, Karola Rühle ${ }^{1,2}$, Leonhard M. Reindl ${ }^{1}$ \\ ${ }^{1}$ University of Freiburg, Department of Microsystems Engineering, 79110 Freiburg, Germany \\ ${ }^{2}$ Fraunhofer Institute for Solar Energy Systems ISE, 79110 Freiburg, Germany
}

\begin{abstract}
The design rules for standard outdoor solar cells are not applicable for cells which are used under low lighting conditions and spectra deviating from AM 1.5. This paper will discuss the major influences on cell efficiencies and their impact on the design of photovoltaic cells for energy selfsufficient sensor systems. This is done for different material classes like crystalline silicon, amorphous silicon and III-V materials.
\end{abstract}

Keywords-energy harvesting; indoor photovoltaics; lowlighting conditions; photovoltaic cells

\section{INTRODUCTION}

Nowadays, solar cells are optimized with respect to the standard test conditions (STC) with the AM 1.5 sun spectrum and an intensity of $1000 \mathrm{~W} / \mathrm{m}^{2}$. In fact, these conditions are rarely given in outdoor applications [1], [2] and especially not for indoor or low lighting applications. A commercially available crystalline silicon solar cell with an efficiency of $18 \%$ abs at STC may only provide efficiencies of less than $5 \%$ abs when it is operated at typical indoor intensities [3], [4]. Similar relations hold for other technologies. The lack of dedicated research on optimizing photovoltaic devices has hindered potential improvement so far. This paper describes the main influences on cell efficiencies that have to be taken into account for a future photovoltaic cell optimization.

\section{MAIN INFLUENCES ON CELL EFFICIENCY}

\section{A. Influence of the Spectrum}

The main influences on the cell efficiency can be differentiated between spectra- and intensity-dependent influences. The spectra-dependence is given for losses due to thermalization, spatial relaxation and non-absorption. These losses relate to the energy gap $E_{\mathrm{g}}$ of the material. Since indoor spectra, for example, contain shorterwavelength radiation, the optimal energy gap shifts towards higher band gaps for indoor lighting (Fig 1).

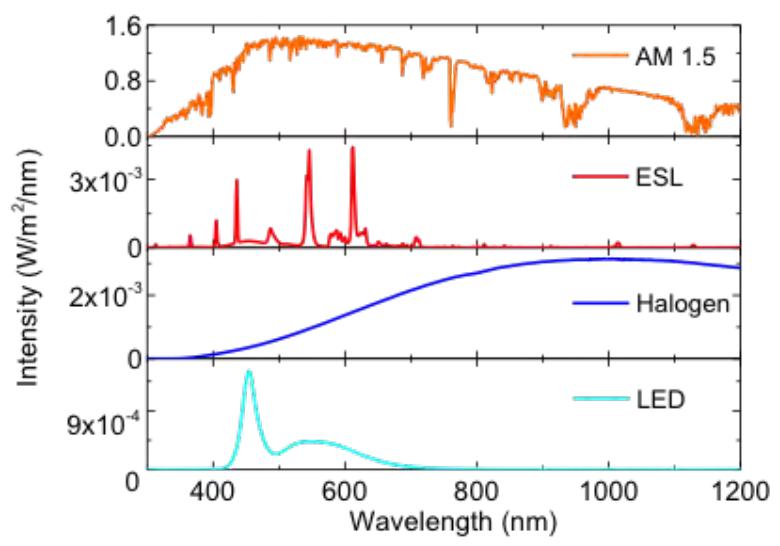

Fig. 1: Spectra for different light sources. AM 1.5 is the spectrum of the sun through an air mass of 1.5 atmospheres, ESL is an energy saving lamp, LED is a white light-emitting diode.

Efficiency losses due to spectral variations are caused by thermalization and non-absorption. Thermalization losses occur if the electron-hole pair is generated by a high-energy photon with energies much higher than the band gap. The energy difference between the photon energy and the band-gap energy is lost to lattice heat, due to thermalization of the electron-hole pair to the band edges. Non-absorption losses occur if the incident photon energy is lower than the band gap energy. The total losses and the contributions discussed above are plotted in figure 2 for different spectra in dependence off the band gap energy.

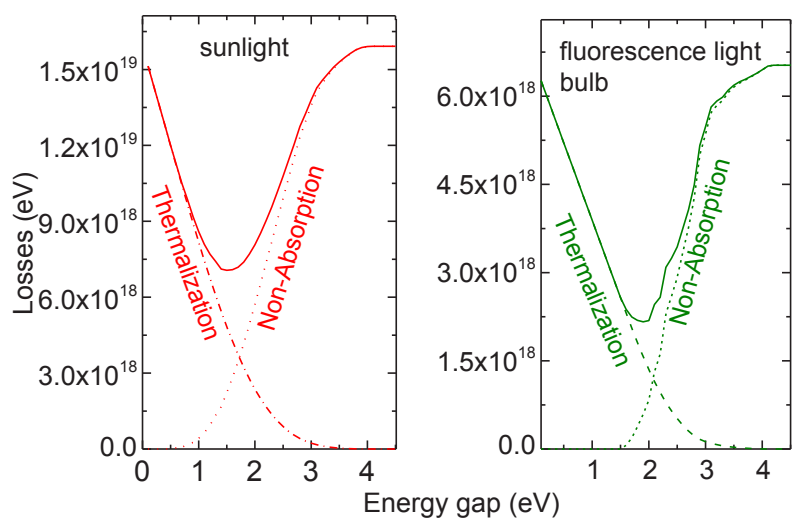

Fig. 2: Thermalization (dash-dot), non-absorption (dot) and total (solid) losses depending on the energy gap of the cell material. [5] 


\section{B. Influence of the light intensity}

The energy conversion efficiency of photovoltaic cell reduces with decreasing light intensity. This is a fundamental effect caused by the thermodynamic principle of detailed balance. The first treatment of such unavoidable losses was performed by Shockley and Queisser [6]. According to their treatment, the currentvoltage characteristic of a photovoltaic cell is given by the one diode model

$$
j(V)=j_{0}\left[\exp \left(\frac{e V}{k T}\right)-1\right]+j_{s c}
$$

where the diode saturation current density $\mathrm{j}_{0}$ is given by the unavoidable radiative recombination rate only and $j_{s c}$ is obtained with an external quantum efficiency of one. For the band gap of silicon, the values are $\mathrm{j}_{\mathrm{sc}}=42 \mathrm{~mA} / \mathrm{cm}^{2}$ [7] and $\mathrm{j}_{0}=5.5 \times 10^{-16} \mathrm{~A} / \mathrm{cm}^{2}$ [6]. Those values are never reached in practice because the typical quantum efficiency is between 90 and $95 \%$ and the dark saturation current is usually much higher because of non-radiative recombination. Besides that, the one diode model is typically extended by the series resistance $R_{S}$ and the parallel shunt resistance.

Fig 3 illustrates the influence of the different parameters in the one diode equivalent circuit model on the power conversion efficiency under realistic conditions for a silicon photovoltaic cell. The full black line corresponds to equation II.1 with the dark saturation current density $\mathrm{j}_{0}=10^{-12} \mathrm{~A} / \mathrm{cm}^{2}$. In general, the diode behavior reduces the efficiency towards low intensities. In addition, the shunt resistance has a strong influence on the low intensity efficiency, while the series resistance influences the high intensity efficiency $(0.1$ to 1 sun, corresponding to 0.01 to $0.1 \mathrm{~W} / \mathrm{cm}^{2}$ ). Solar cell designs for low irradiation intensities thus have the opposite optimization rules regarding series and shunt resistance, when compared to standard outdoor cells operating under one sun intensity conditions.

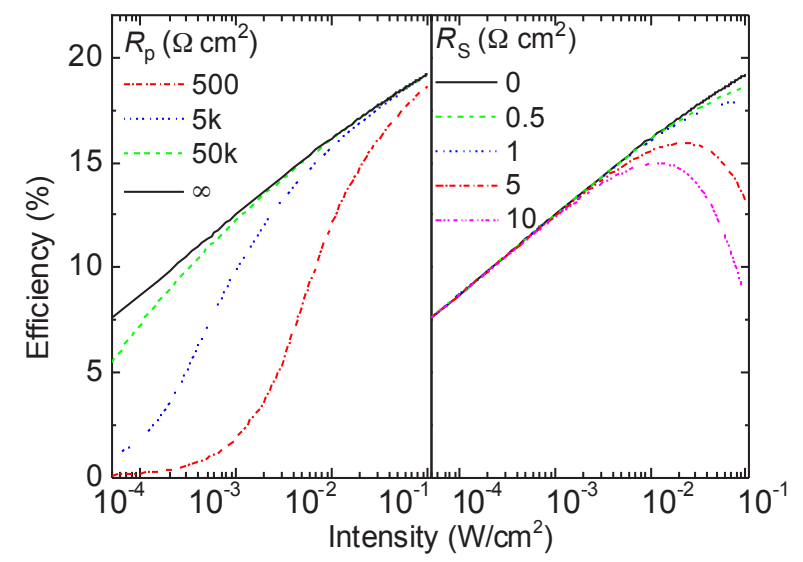

Fig. 3: Variation of efficiency with irradiation intensity for (left) a variation of the shunt resistance $R_{p}$ and (right) a variation of the series resistance $\mathrm{R}_{\mathrm{s}}$. Typical values for standard outdoor solar cells are in the range of $R_{p}=5 \mathrm{kOhm}$ and $\mathrm{R}_{\mathrm{s}}=0.5 \mathrm{Ohm} \mathrm{cm}^{2}$. [5]
Similar observations have been made by Randall et al. in experimental measurements on solar cells (Fig 4).

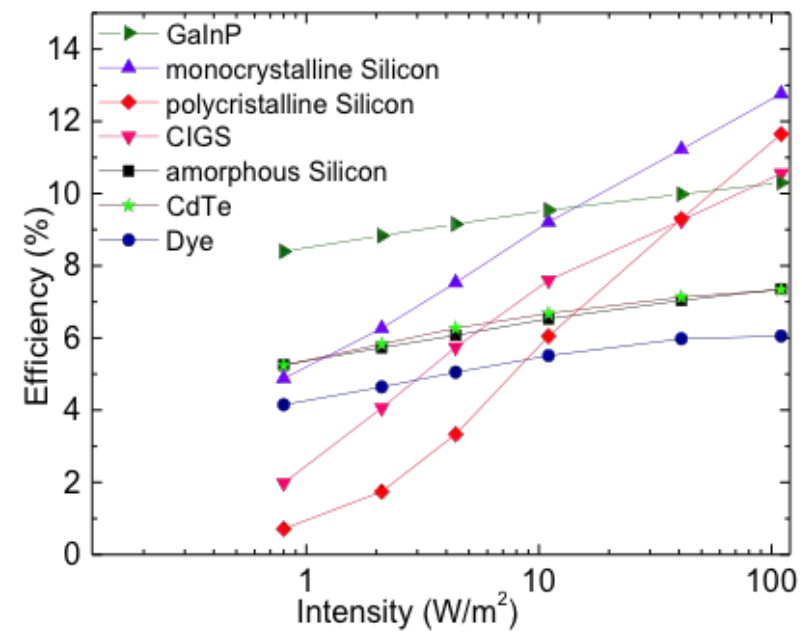

Fig. 4: Measuremements taken by Randall et al. [3] on different types of solar cells.

\section{THE POTENTIAL OF DIFFERENT TECHNOLOGIES}

The world record power conversion efficiency for different technologies are shown in Fig 5. These efficiencies are measured for AM1.5 conditions, which means an intensity of $100 \mathrm{~mW} / \mathrm{cm}^{2}$. The different colors indicate different technology groups.

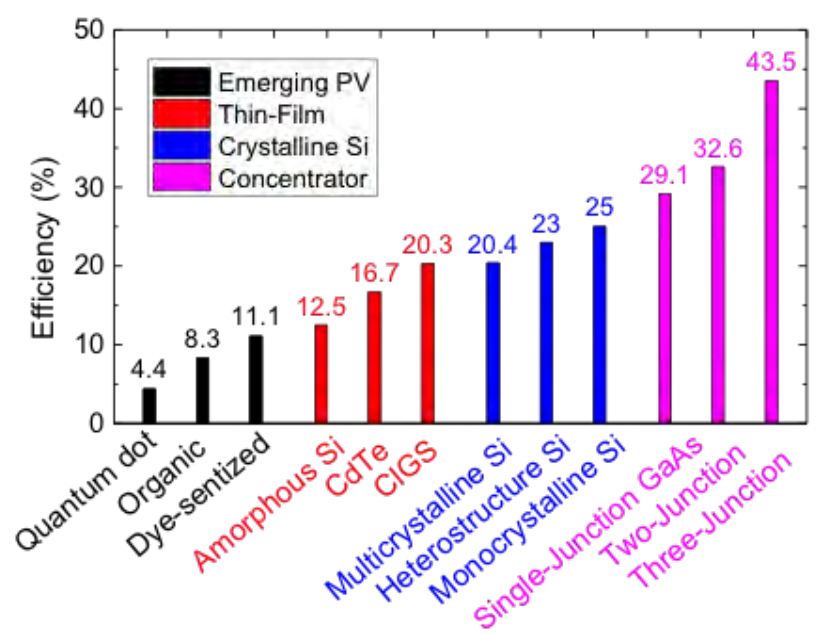

Fig. 5: Research world record efficiencies 2012 (data from NREL).

The emerging PV technologies, like a quantum dot or dye-sensitized solar cells, reach the lowest record efficiencies. Typical efficiencies are far below $10 \%$, especially for industrially available cells. Even though the 
technologies show a quite weak efficiency drop towards low intensities, efficiencies in this intensity range are between zero and 5\%. A further deficiency of this technology type is still the low long-term stability of the materials used.

The class of next higher efficiencies is amorphous thinfilm technologies, like amorphous silicon or CIGS. Cells in this technology group show record efficiencies between 10 and $20 \%$. These technologies are already industrially established. However, the record efficiency for industrially available CIGS cells is still only around $12 \%$. At least in the measurements shown in Fig. 4, the CIGS cells show a weak shunt, limiting the low intensity efficiency to values below 5\%. Whether processes exist that avoid this shunting is unclear.

Crystalline silicon solar cells form a class of record efficiencies between 20 and $25 \%$ at one sun. Silicon solar cell processing is industrially well established and very cheap. Typical industrial cells, however, show a strong decrease towards low efficiencies (eg. Fig 4). This is due to an unoptimized shunt resistance in the order of $5 \mathrm{k} \Omega$ that is typically sufficient for outdoor use, but not for low intensity applications. It has, however, been shown [8] that such shunts can be avoided with rather simple measures, leading to experimentally demonstrated efficiencies in the order of $16 \%$ at $1 \mathrm{~W} / \mathrm{m}^{2}$. Flexible silicon solar cells have also been demonstrated with high efficiencies [9].

The highest record efficiencies are reached by cells made from III-V materials. They range from $29 \%$ for a single junction cell up to $43.5 \%$ for a multi-junction cell. From the pure efficiency point of view, cells from this materials would be considered best for small-area application at low intensities. However, the area price for this class is so high that widespread application in sensor systems is seen as unlikely. Multi-junction cells have complex requirements regarding the current matching between the different junctions which limits their applicability under varying spectral conditions.

\section{CONCLUSION AND OUTLOOK}

Solar cells for energy harvesting applications need to be optimized with respect to their spectral response and their low intensity efficiency. Shunting and other parasitic currents in parallel to the diode need to be avoided for a good low-intensity performance. Although the band gap of silicon is not optimized for many indoor lighting spectra, the overall high efficiency and the low price of this technology makes them very feasible for energy harvesting. This holds even more if a flexible application indoors as well as outdoors is intended. Our further research is therefore focused on the improvement of silicon photovoltaic cells in the low intensity range. A concept allowing for industrial large-scale production of such optimized cells will be developed.

\section{ACKNOWLEDGMENT}

The authors gratefully acknowledge the financial support of the German Research Foundation (GRK 1322).

\section{REFERENCES}

[1] A. Parretta, A. Sarno, and L. R. M. Vicari, "Effects of solar irradiation conditions on the outdoor performance of photovoltaic modules," Optics Communications, vol. 153, no. 1-3, pp. 153-163, Jul. 1998.

[2] K. Bücher, "Site dependence of the energy collection of PV modules," Solar Energy Materials and Solar Cells, vol. 47, no. 1-4, pp. 85-94, Oct. 1997.

[3] J. F. Randall and J. Jacot, "Is AM1.5 applicable in practice? Modelling eight photovoltaic materials with respect to light intensity and two spectra," Renewable Energy, vol. 28, no. 12, pp. 1851-1864, Oct. 2003.

[4] K. Rühle, M. Freunek, L. M. Reindl, and M. Kasemann, "Designing photovoltaic cells for indoor energy harvesting systems," in Systems, Signals and Devices (SSD), 2012 9th International MultiConference on, 2012, pp. 1-5.

[5] K. Ruhle, S. W. Glunz, and M. Kasemann, "Towards new design rules for indoor photovoltaic cells," in Photovoltaic Specialists Conference (PVSC), 2012 38th IEEE, 2012, pp. 002588-002591.

[6] W. Shockley and H. J. Queisser, "Detailed Balance Limit of Efficiency of p-n Junction Solar Cells," Journal of Applied Physics, vol. 32, no. 3, pp. 510-519, Mar. 1961.

[7] P. Würfel, Physics of Solar Cells: From Principles to New Concepts. Weinheim: Wiley-VCH, 2005.

[8] S. W. Glunz, J. Dicker, M. Esterle, M. Hermle, J. Isenberg, F. J. Kamerewerd, J. Knobloch, D. Kray, A. Leimenstoll, F. Lutz, D.

Osswald, R. Preu, S. Rein, E. Schaffer, C. Schetter, H. Schmidhuber, H. Schmidt, M. Steuder, C. Vorgrimler, and G. Willeke, "High-efficiency silicon solar cells for low-illumination applications," in Conference Record of the Twenty-Ninth IEEE Photovoltaic Specialists Conference, 2002 , pp. $450-453$.

[9] S. W. Glunz, "New concepts for high-efficiency silicon solar cells," Solar Energy Materials and Solar Cells, vol. 90, no. 18-19, pp. 32763284, Nov. 2006. 